\title{
TWO NEW SPECIES OF TYPHLOCHARIS DIECK, 1869 (COLEOPTERA, CARABIDAE) FROM PORTUGAL: DESCRIPTION AND NOTES ON RELATED SPECIES
}

\author{
A. R. M. Serrano* \& C. A. S. Aguiar**
}

\begin{abstract}
The present study describes two endogean carabid species of Typhlocharis Dieck, Typhlocharis rochapitei $\mathbf{n}$. sp. and Typhlocharis crespoi $\mathbf{n}$. sp., belonging to the T. diec$k i$ species group and to the $T$. outereloi species group, respectively. The work provides diagnostic characters and in particular, the structure of male genitalia. Affinities to putative relatives and keys for the identification of the diecki (all species) and outereloi (Portugal) species groups are also given.
\end{abstract}

Key words: Coleoptera, Carabidae, Anillina, Typhlocharis, diecki and outereloi groups, new species, Portugal.

\section{RESUMEN}

Dos nuevas especies del género Typhlocharis Dieck, 1869 de Portugal y notas sobre especies relacionadas (Coleoptera, Carabidae)

Se describen dos nuevas especies de carábidos Anillini endogeos (Coleoptera: Carabidae) de Portugal, Typhlocharis rochapitei n. sp. y Typhlocharis crespoi n. sp., pertencientes a los grupos diecki y outereloi, respectivamente. Se destacan los caracteres que las definen y, en particular, la estructura de la genitalia masculina. Se discute la afinidad con las especies más relacionadas y además se aportan datos ecológicos. Por último, se incluyen claves de todas las especies conocidas del grupo diecki y de las especies del grupo outereloi conocidas en Portugal.

Palabras clave: Coleoptera, Carabidae, Anillini, Typhlocharis, grupos diecki y outereloi, nuevas especies, Portugal.

\section{Introduction}

Within the subtribe Anillina and according to the catalogue of the ground beetles of the Iberian Peninsula (Serrano, 2003) plus some more recent works (Ortuño, 2005; Serrano et al., 2005; Serrano \& Aguiar, 2006a, 2006b; Andújar et al., 2008) the genus Typhlocharis Dieck, 1869 (Coleoptera: Carabidae: Trechinae: Bembidiini) is the richest one in this Peninsula with 46 known species. Species of

* Centro de Biologia Ambiental/Departamento de Biologia Animal, Faculdade de Ciências da Universidade de Lisboa, R. Ernesto de Vasconcelos, C2, 1749-016 Lisboa, Portugal.

** Centro de Biologia Ambiental. Faculdade de Ciências da Universidade de Lisboa, R. Ernesto de Vasconcelos, C2, $1^{\circ}$ Piso, 1749-016 Lisboa, Portugal. 
Typhlocharis are distributed throughout the Iberian Peninsula (Europe), Morocco and Tunisia (North Africa) (Jeannel, 1963). Representatives of this genus have been found in the vestiges of the Lusitanian, the Lionigurian, the Betic Riffian and the Numidian Massifs and the genus is considered a very old one (Jeanne, 1973). According to Jeannel (1963) the ancestral lucicolous of the Typhlocharis expanded from Africa to the Betic Riffian Massif. Taking into account the more recent knowledge of the structure of the Western Mediterranean from the end of the Mesozoic to the end of the Pleistocene (Oosterbroek \& Arntzen, 1992; Andeweg, 2002), the land connections between the Iberian Península and North Africa occurred during the Oligocene and most probably during the Miocene. So, the present distribution of Typhlocharis may be dated from 25$30 \mathrm{MY}$ onwards. Some comments on the origin and evolution of this genus can be found also in the recent work of Andújar et al. (2008).

All species of this genus are endogean carabids, wingless (apterous) and eyeless (anophtalmous), occurring and moving very slowly in soil. They may also be collected on the bottom surface of stones more or less deeply buried in the soil. The majority of species of Typhlocharis are local or regional endemisms with restricted distributions, probably because of isolation by physical barriers and low dispersal ability. Thus, taking into account their present distribution, they represent a great potential for phylogeographic studies.

In recent years the knowledge related to the systematics and distribution of representatives of the genus Typhlocharis from Portugal has considerably increased (Serrano \& Aguiar, 2000, 2001, 2002, 2006a, 2006b; Serrano et al., 2005). So far there are twelve known species recorded for Portugal (Coiffait, 1968, 1971; Serrano \& Aguiar, op. cit; Serrano et al., op. cit), belonging to four species groups (sensu Zaballos \& Ruiz-Tapiador, 1997).

The aim of this work is to describe two new species of the genus Typhlocharis for Portugal, one in the diecki group and the other in the outereloi group. Representatives of both groups were already known from Portugal (e.g. Coiffait, 1968; Serrano \& Aguiar, 2000, 2006a). We also provide notes about relationships of these species with the closest forms. Moreover we give keys to all known species of the diecki species group and to the outereloi species group from Portugal.

According to Zaballos \& Ruiz-Tapiador (1997) the adults belonging to the species of the diecki and outereloi groups are recognized by the following combination of characters: diecki group, a) umbilicate series of elytra with four setae in the anterior group and three setae in the posterior group $(4+3)$ and b) apical edge of elytron with no more than two teeth; outereloi group, a) umbilicate series of elytra with four setae in the anterior group and one-two setae in the posterior group $(4+1$ or $4+2)$ and b) apical edge of elytron with no more than two teeth. The eight known species of the diecki Group were found in Spain, Tunisia and Portugal (Andújar et al., 2008). On the other hand, the fifteen known species of the outereloi group can be found in several regions of Portugal and Spain (e.g. Serrano, 2003).

\section{Material and methods}

Field work was conducted within the Province of Estremadura in the vicinity of Lisbon region and in some localities throughout the Province of Algarve (both Provinces of Portugal); this resulted in the collection of specimens of endogean beetle species of the subtribe Anillina in two localities (Alcabideche and Pincho, respectively in Estremadura and Algarve Provinces). After a careful study, we concluded that the specimens represent two new species of the genus Typhlocharis, belonging to the diecki and outereloi groups. The specimens were collected by direct hand collecting on the bottom surface of deeply buried stones in fragments of pristine-type Mediterranean forest habitats dominated by holmoak bushes (Quercus coccifera Linnaeus) (Alcabideche) or in fragments of habitats dominated by lentisk bushes (Cistus ladanifer Linnaeus) (Pincho). Additional specimens were obtained from samples

Figs. 1-8. - Typhlocharis rochapitei n. sp.: 1) head and anterior part of pronotum (dorsal view), 2) head (ventral view), 3) stridulatory organ (pars stridens), 4) head (part), pronotum and anterior part of elytra (dorsal view), 5) elytra (left latero-dorsal view), 6) elytra (apical view), 7) thorax (part) and abdomen (male, ventral view), 8) thorax (part) and abdomen (female, ventral view).

Figs. 1-8. - Typhlocharis rochapitei n. sp.: 1) cabeza y parte anterior del pronoto (vista dorsal), 2) cabeza (vista ventral), 3) órgano estridulador (pars stridens), 4) cabeza (parte), pronoto y parte anterior de los élitros (vista dorsal), 5) élitros (vista esquierda laterodorsal), 6) élitros (vista apical), 7) tórax (parte) y abdomen (macho, vista ventral), 8) tórax (parte) y abdomen (hembra, vista ventral). 

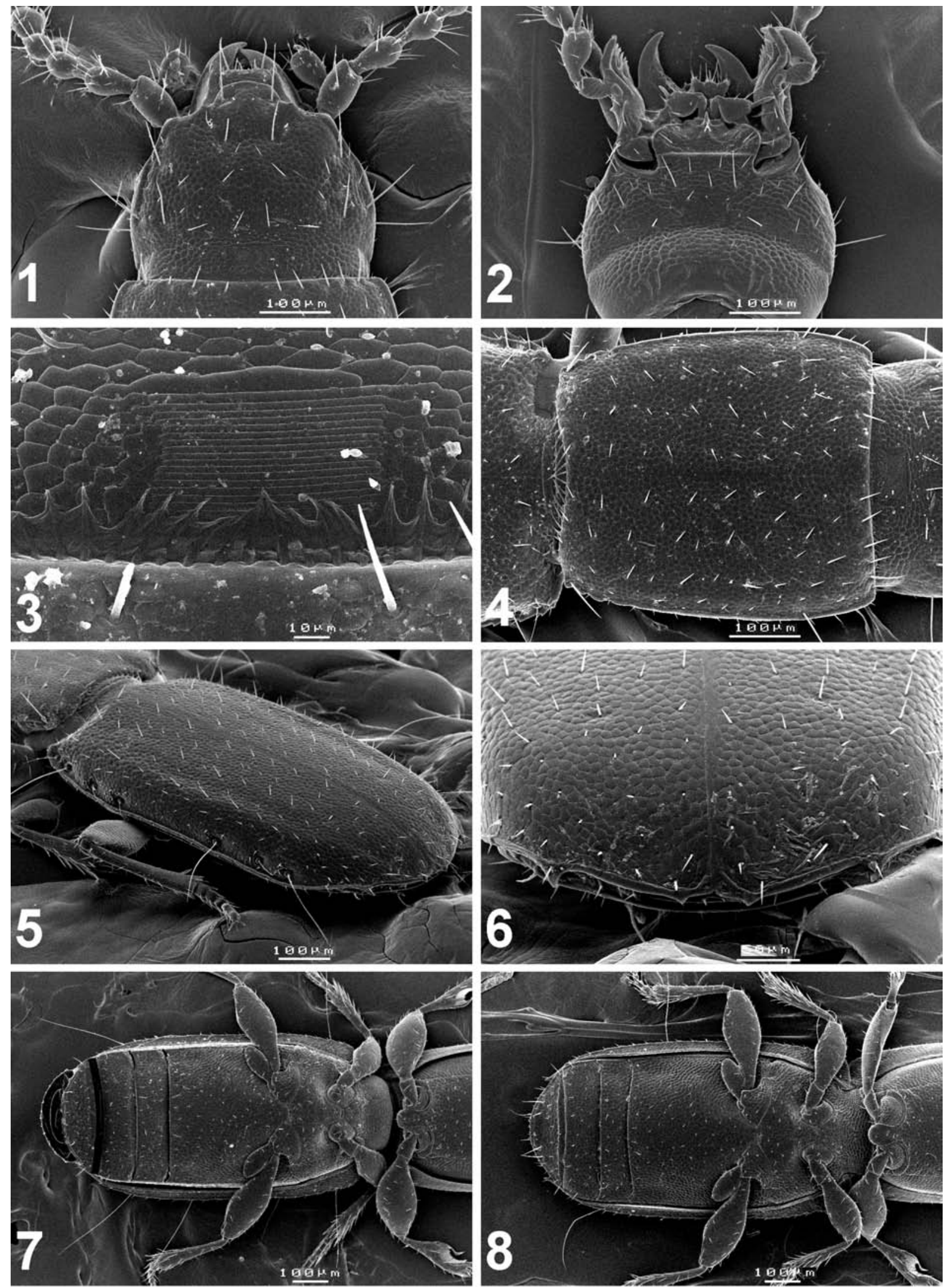

Graellsia, 64(2), Diciembre 2008, pp. 281-293 - ISSN: 0367-5041 
of soil taken from the above-mentioned localities using Berlese apparatus.

The morphological study of adult specimens was done using a scanning electron microscope JEOL JSM-5200 LV. Measurements and drawings were done with a Wild M5 stereoscopic microscope equipped with a dissecting microscope ocular micrometer and a drawing tube.

The distribution of species in the descriptions is given in U.T.M. coordinates (1 km x $1 \mathrm{~km})$.

\section{Taxonomic description}

\section{Typhlocharis rochapitei $\mathrm{n}$. sp.}

(Figs. 1-8, 17A and B, 18A)

TyPICAL SerIE. Holotype $\sigma^{7}$ : Portugal, Alcabideche (Estremadura Province) (UTM: 29SMC6288), 7.IV.2006. Paratypes: same locality, 7.IV.2006, $3 \sigma^{7} \sigma^{7}$ and 2 우 $\left(2 \sigma^{7} \sigma^{7}\right.$ and 1 \& gold coated), 28.V.2008, 2 우. Holotype and paratypes deposited in the collection of the senior author, Department of Animal Biology (Lisbon).

Diagnosis: Anophtalmous, body parallel, depressed, brown, with integument microreticulate, with scattered pubescence. Elytron with six discal rows of setae, impair rows with setae bigger than the ones of the pair rows; seven $(4+3)$ marginal umbilicate setae; apical edge not sinuate, with one tooth at the ending of seventh stria region, one slightly parasutural tooth (males and females). Hind trochanters round-shaped in both sexes. Abdominal female sterna II and III with one common faint lateral fovea on each side. Aedeagus (Figs. 17A and B) with the median lobe sickleshaped, basal lamina markedly arcuate, the apex bent to left (dorsal view); internal sac diffuse, with a twisted sclerite and tangled membranes; left and right parameres with two apical seta.

DESCRIPTION: Length of Holotype: $1.8 \mathrm{~mm}$. Length of paratypes: $1.6 \mathrm{~mm}$ (males), $1.7-1.8 \mathrm{~mm}$ (females). Head (Figs. 1-2) slight wider than long [length: 0.31-0.34 mm (males) and 0.32-0.34 (females), width: 0.34-0.39 mm (males) and 0.40$0.43 \mathrm{~mm}$ (females)] with penta and hexagonal microsculpture; vertex with transversal microsculpture arranged in parallel ridges to form a file (pars stridens) in the area below the anterior margin of pronotum (Fig. 3). Cephalic chaetotaxy (large setae): Labrum with three pairs of setae (those on sides longer), one pair on sides of clypeus and one pair close to frontal sulcus, two pairs of supraocular setae (anterior and posterior) and 1-2 pairs of setae on the posterior region between vertex and lateral carinae. Antennae moniliform, mouth-parts (Fig. 2) with no special features, as for other members of the genus. Pronotum rectangular (Fig. 4), slightly longer than wide (1.0-1.1 times) [length: $0.43-0.50 \mathrm{~mm}$ (males) and 0.50-0.54 (females), width: $0.42-0.46 \mathrm{~mm}$ (males) and $0.47-0.50 \mathrm{~mm}$ (females)], with hexagonal microsculpture, slightly narrowed towards posterior angles which are dentate; disk flattened, with one central and one lateral slight sulcus on each side; anterior margin slightly arcuate; lateral margins with 2 or 3 minor denticles near the posterior angles; disk faintly depressed near the posterior margin, this slightly expanded on each side and strongly arcuate in the middle region. Chaetotaxy: 3-4 irregular longitudinal series of minute setae between midline and lateral margins directed anteriad and inward; one anterior seta on each side in anterior quarter, one posterior seta on hind angle; five-six pairs of setae near the anterior margin. Elytra (Fig. 5) 1.8-1.9 times longer than wide [length: 0.80-0.91 mm (males) and 0.90-0.96 $\mathrm{mm}$ (females)], width: $0.43-0.50 \mathrm{~mm}$ (males) and $0.50-0.53 \mathrm{~mm}$ (females)], with hexagonal microsculpture, parallel and oval posteriorly, with a faint longitudinal carinae at the beginning of seventh stria; flattened on the disk; transverse scutellar organ present near the base of suture; scutellar region not punctured; humeral angles well marked and rounded, with a tooth in the base of carinae; lateral margins serrate, teeth decreasing in size posteriorly; apical margin not sinuate after the end of longitudinal carina, with one tooth coinciding with end of seventh stria, presence of a small parasutural denticle (Figs. 5-6). Chaetotaxy: part of the pubescence of the disk is arranged in six lines since the sutural region, setae of impair rows are bigger than the ones of pair rows, all these setae are erect and slightly directed anteriad; none large discal setae are present; umbilicate series with 4 setae in the front group and 3 in the hind group (4+3) (Fig. 5 ). Legs with robust femora; males with inner margin of intermediate femur very slightly dentate (Fig. $7)$; trochanters of third pair similar in male and female, without special features (Figs. 7-8), protarsus of male without dilated segments. Abdomen (Figs. 7-8) with sternum II of male without trace of lateral fovea (Fig. 7), female sterna II and III with one faintly joint lateral fovea on each side (Fig. 8). Male genitalia (Figs. 17A and B) in lateral aspect with median lobe strongly sickle-shaped, basal lamina markedly arcuate (Fig. 17A); median lobe in dorsal aspect (Fig. 17B) with apex acute, bent to left; internal sac with one twisted sclerite and tangled membranes; left paramere with two apical 


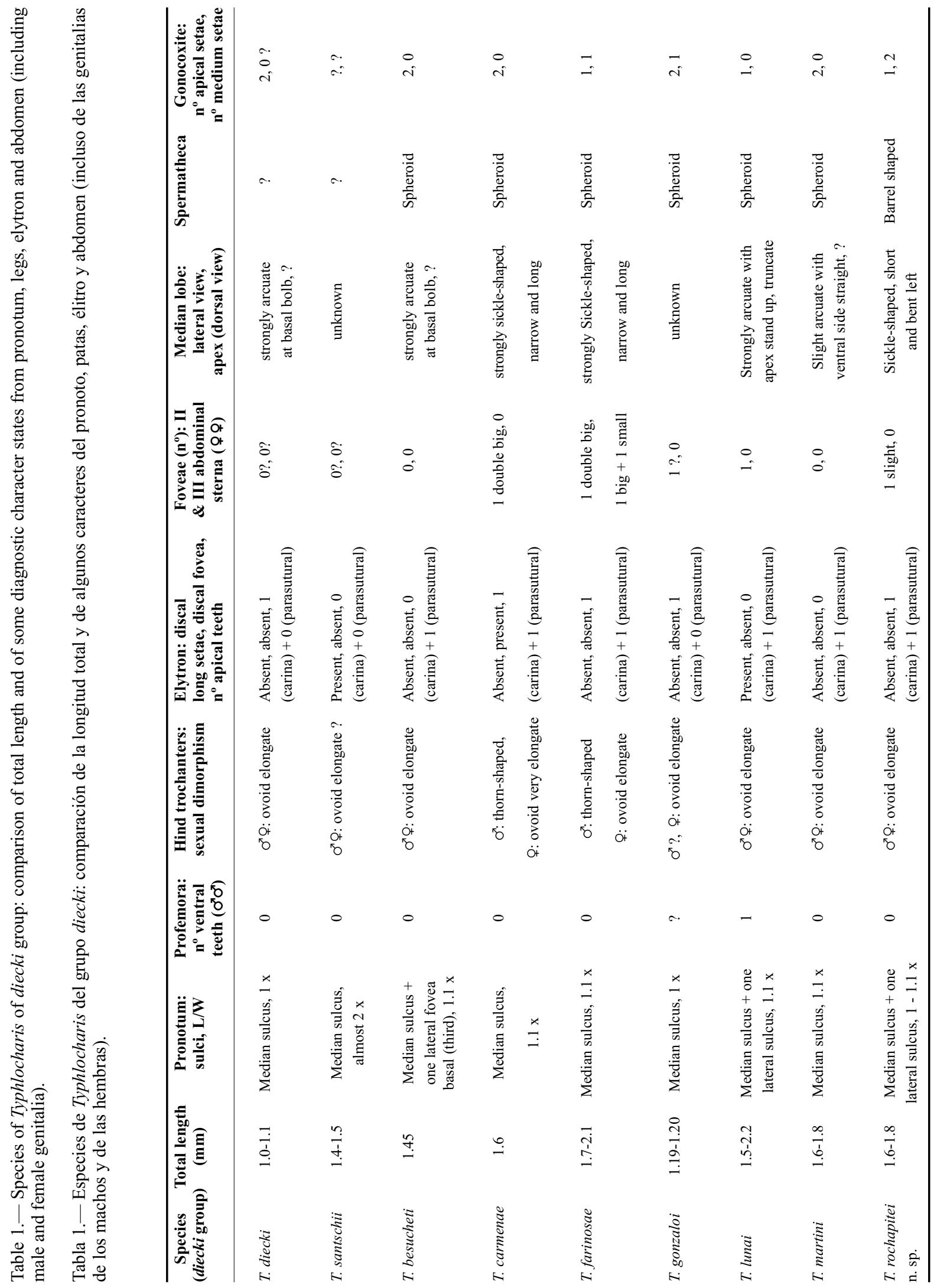


setae, dorso-basal edge expanded; right paramere with two apical setae. Female genitalia (Fig. 18A) with gonocoxites of ovipositor weakly sclerotized, each one in ventral aspect with one apical seta and two medium setae, the proximal bigger than the basal one; internal genital tract with spermathecal duct short and spermatheca barrel shaped, spermathecal gland long, with proximal region membranous and apical region more or less sclerotized.

ETYMOLOGY: This new species is dedicated to Professora Maria Teresa Rocha Pité, a Portuguese entomologist and evolutionary ecologist, who greatly contributed to the taxonomic and ecological knowledge of the Diptera Drosophilidae, mainly of Portugal.

Affinities (see also Table 1): The new species belongs to the diecki group based on the umbilicate series setae pattern $(4+3)$, presence of one parasutural tooth and anterior margin of clypeus not dentate. It is well differentiated from all the species within this group, among other features, by the shape of aedeagus (particularly median lobe, including apex in dorsal view). Within the diecki group the pronotum of $T$. rochapitei $\mathrm{n}$. $\mathrm{sp}$. presents one lateral slight longitudinal sulcus on each side like $T$. lunai Serrano \& Aguiar, 2006. The new species shares with the majority of species except $T$. santschii Normand, 1915 and $T$. lunai the absence of three long discal setae on the elytron. Typhlocharis rochapitei $\mathrm{n}$. sp., as well as T. lunai, T. carmenae Zabalos \& Ruiz-Tapiador, 1994 and T. farinosae Zabalos \& Ruiz-Tapiador, 1997 bear a posteriolateral fovea on each side of abdominal sternum II in females. The hind trochanters of males are ovoid elongate, not thorn-shaped as happens in T. carmenae and T. farinosae. The form of the spermathecae of T. lunai, T. besucheti Vigna-Taglianti, 1972, T. carmenae, T. farinosae, T. gonzaloi Ortuño, 2005 and T. martini Andújar, Lencina \& Serrano, 2008 are si-milar (spheroid), while in the new species it is barrel shaped. The number of apical gonocoxite setae is one like in T. lunai and T. farinosae (2 in $T$. besucheti, T. carmenae, T. gonzaloi and T. martini).
Apparently only $T$. farinosae and $T$. gonzaloi bear one medium seta in the gonocoxite while $T$. rochapitei $\mathrm{n}$. sp. presents two setae (Fig. 18A).

Taking into account the analysed characters, it is very hard to say to which species $T$. rochapitei $\mathrm{n}$. $\mathrm{sp}$. is more akin within the diecki group.

The morphological study of adult specimens of the new species, using a scanning electron microscope, allowed us to verify that the internal edge of intermediate tibiae of males does not bear a long seta near the apical margin, as well as the elevation in posterior margin of abdominal sternum IV of females, features that were found in T. lunai (Serrano \& Aguiar, 2006a). Abdominal sternum II in males are not tuberculate near the posterior margin either.

As a final remark, we would like to point out that $T$. rochapitei $\mathrm{n}$. $\mathrm{sp}$. is the second species recorded for Portugal, belonging to the diecki group. This group has a large distribution area that includes most parts of the Iberian Peninsula and Tunisia (Algeria and North Morocco are not yet well known concerning the Typhlocharis fauna). The finding of $T$. lunai and now $T$. rochapitei sp. n. in Portugal agrees with this large distribution (see Serrano \& Aguiar, 2006a, Figs. 26 and 27).

It is interesting to note that in the locality of Alcabideche, where T. rochapitei $\mathrm{sp}$. n. was discovered, lives also a new species of the endogean genus Geocharis Ehlers, 1883 (Serrano \& Aguiar, in press). Both species are partially syntopic.

\section{Typhlocharis crespoi n. sp.}

(Figs. 9-16, 17C and D, 18B)

Typical Serie. Holotype $\sigma^{x}$ : Portugal, Pincho (Algarve) (UTM: 29SNB2218), 10.III.2004. Paratypes: same locality, 2.II.2006, $1 \sigma^{\top}, 4$.V.2006, $3 \sigma^{7} \sigma^{\top}$ and 2 우 (2 $\sigma^{\top} \sigma^{\top}$ and 1 우 gold coated). Holotype and paratypes deposited in the collection of the senior author, Department of Animal Biology (Lisbon).

DiAGNOSIS: Anophtalm, body parallel, depressed and brownish-yellow; integument microreticulate, with scattered pubescence. Elytron with $6(4+2)$

Figs. 9-16.- Typhlocharis crespoi n. sp.: 9) head (dorsal view), 10) head (ventral view), 11) posterior region of head amplified (dorsal view), 12) head (part), pronotum and anterior part of elytra (dorsal view), 13) elytra (left latero-dorsal view), 14) elytra (apical view), 15) thorax (part) and abdomen (male, ventral view), 16) thorax (part) and abdomen (female, ventral view).

Figs. 9-16.- Typhlocharis crespoi n. sp.: 9) cabeza y parte anterior del pronoto (vista dorsal), 10) cabeza (vista ventral), 11) region posterior de la cabeza ampliada (vista dorsal), 12) cabeza (parte), pronoto y parte anterior de los élitros (vista dorsal), 13) élitros (vista esquierda latero-dorsal), 14) élitros (vista apical), 15) tórax (parte) y abdomen (macho, vista ventral), 16) tórax (parte) y abdomen (hembra, vista ventral). 

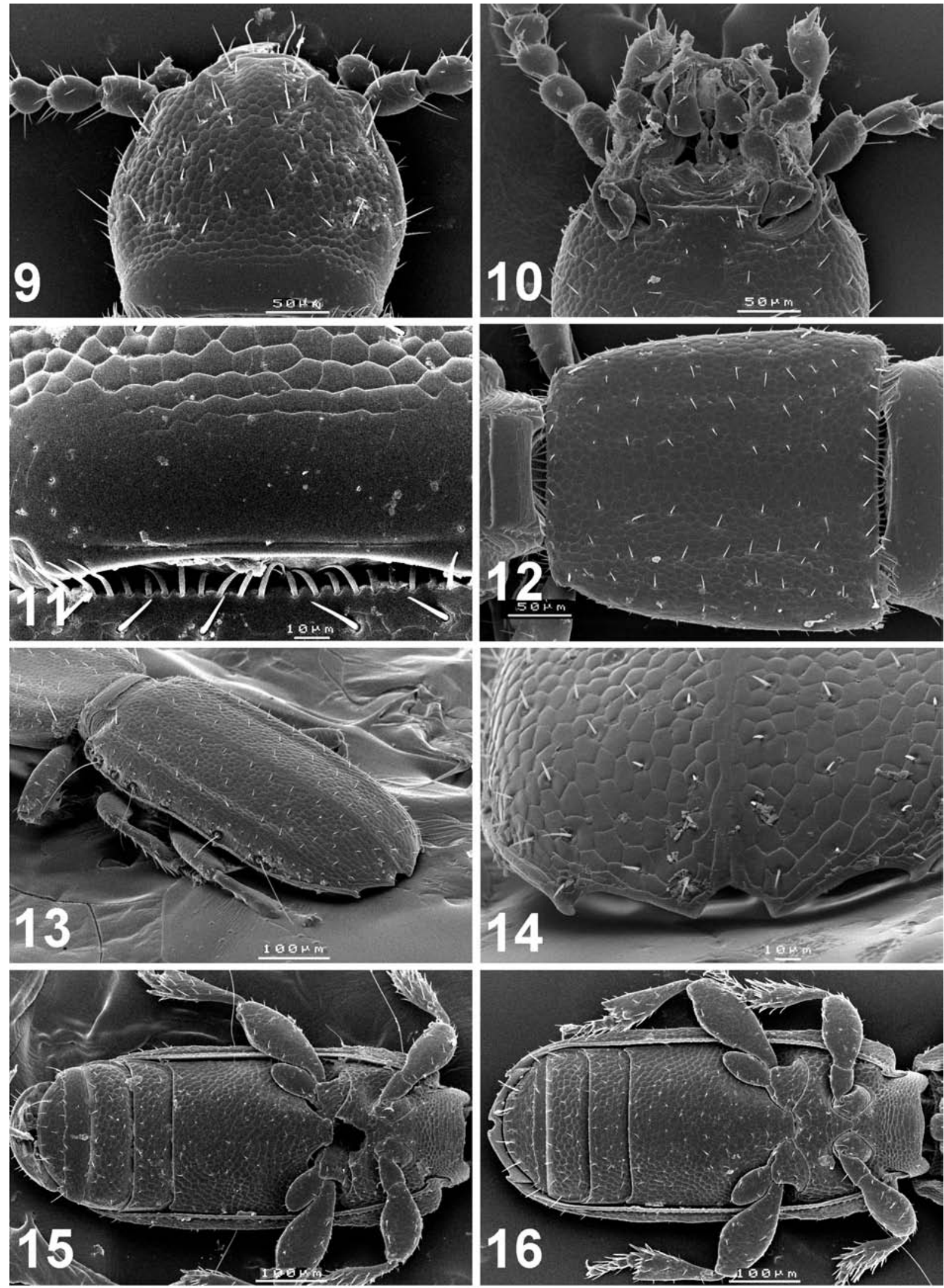

Graellsia, 64(2), Diciembre 2008, pp. 281-293 - ISSN: 0367-5041 


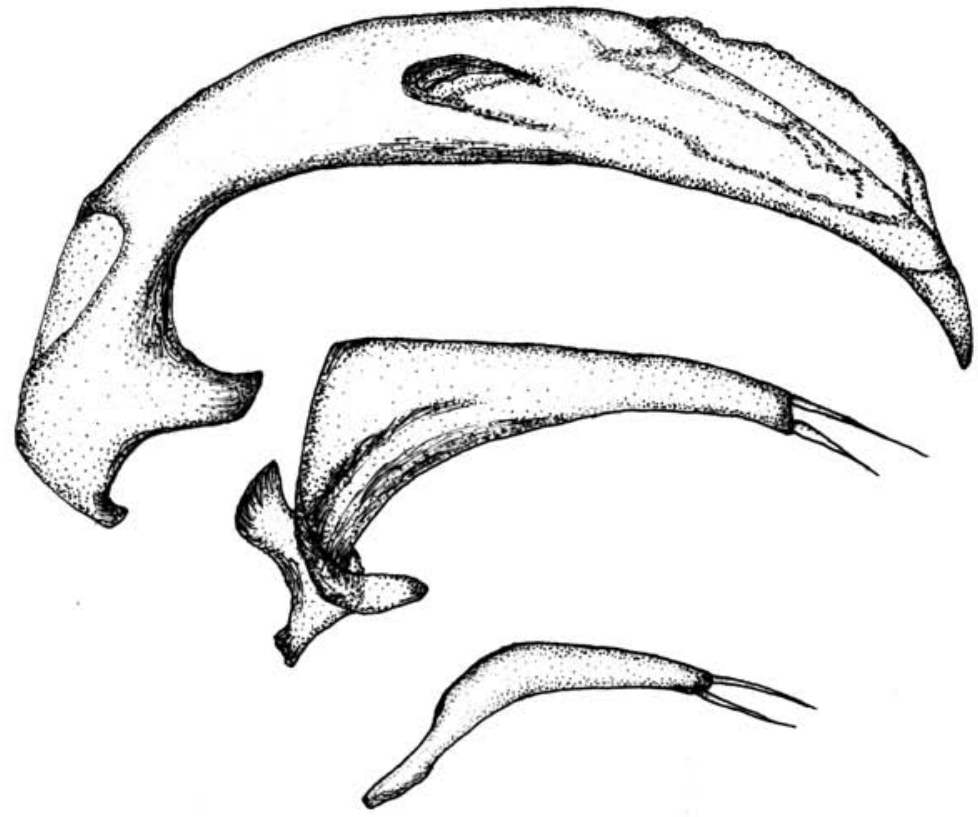

A
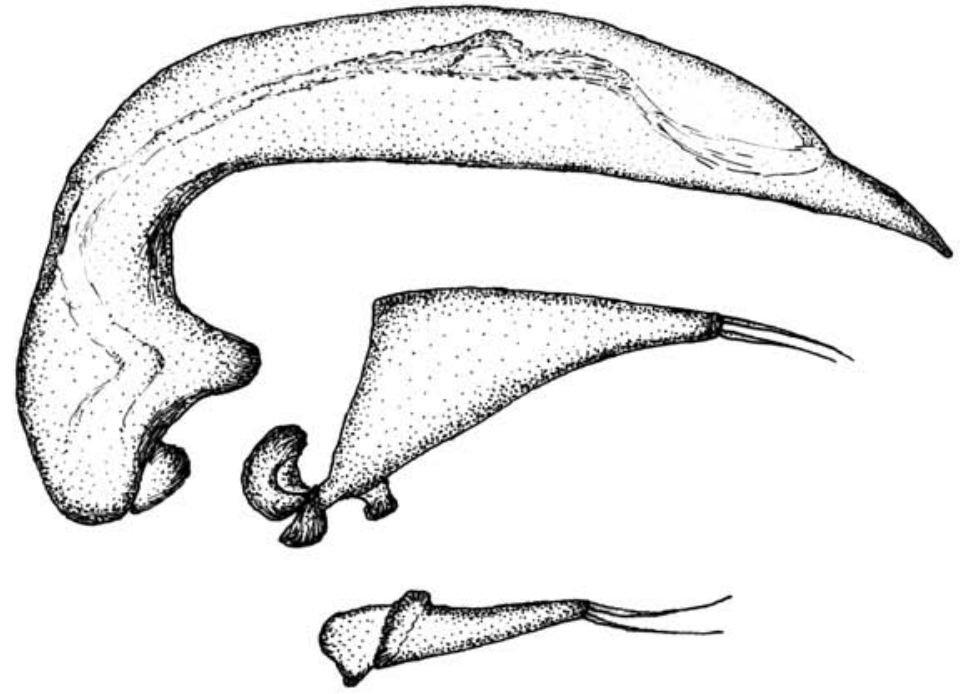

C
$0.1 \mathrm{~mm}$

\section{$0.1 \mathrm{~mm}$}

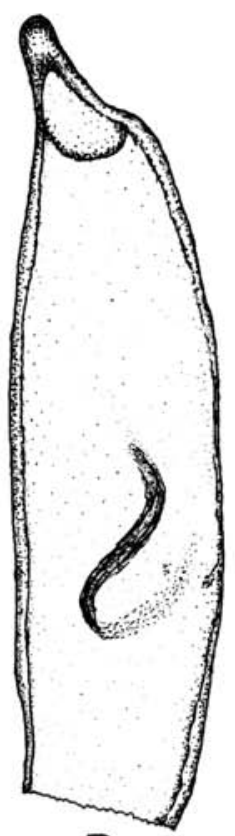

B

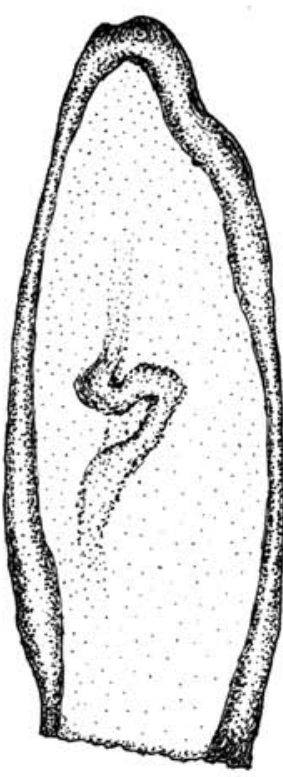

D

Fig. 17.- Typhlocharis rochapitei $\mathbf{n}$. sp.: median lobe of aedeagus and left paramere in lateral view (A) and median lobe of aedeagus in dorsal view (B); Typhlocharis crespoi n. sp.: median lobe of aedeagus and left paramere in lateral view (C) and median lobe of aedeagus in dorsal view (D).

Fig. 17.- Typhlocharis rochapitei n. sp.: lóbulo mediano del edeago y parámero izquierdo en vista lateral (A) y lóbulo mediano del edeago en vista dorsal (B); Typhlocharis crespoi n. sp.: lóbulo mediano del edeago y parámero izquierdo en vista lateral (C) y lóbulo mediano del edeago en vista dorsal (D). 


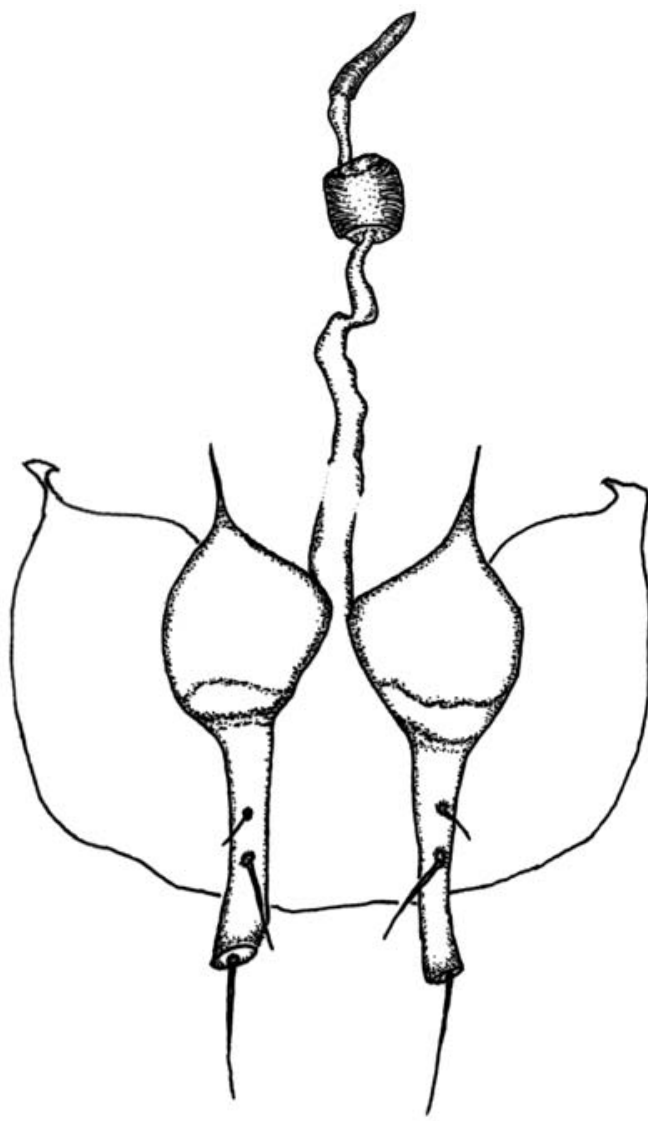

A

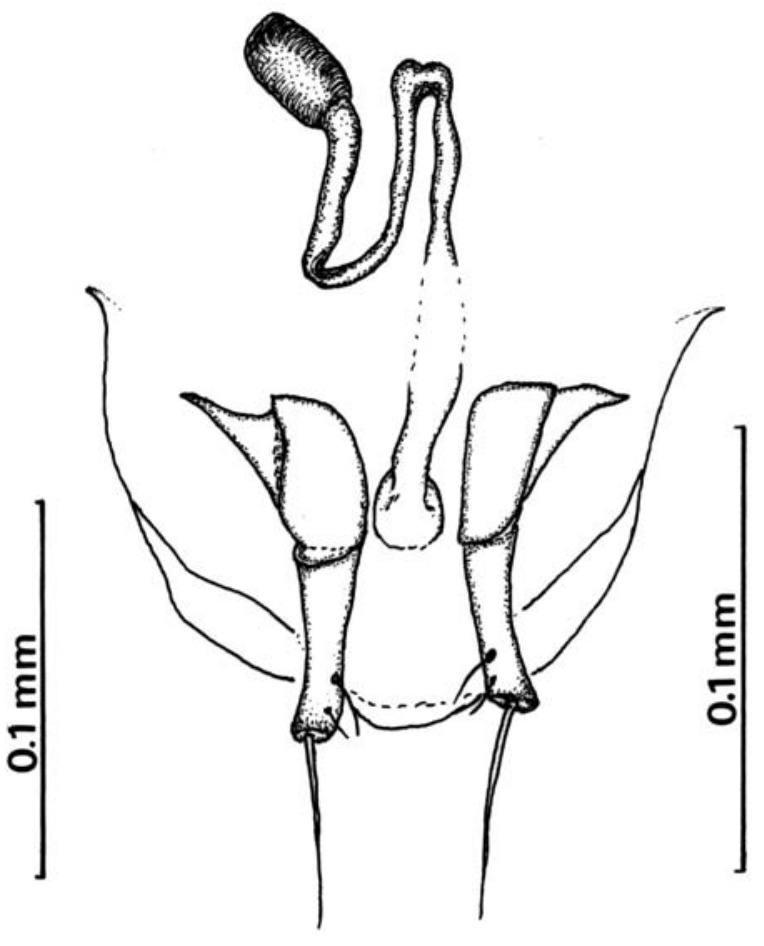

B

Fig. 18. - Female genitalia (ventral view): Typhlocharis rochapitei n. sp. (A) and Typhlocharis crespoi n. sp. (B).

Fig. 18. - Genitalia de la hembra en vista ventral: Typhlocharis rochapitei n. sp. (A) y Typhlocharis crespoi n. sp. (B).

marginal umbilicate setae; apical edge with one tooth at the ending of seventh stria region (males and females), parasutural one present. Hind trochanters round-shaped in both sexes. Hind femora robust, strongly expanded in the middle region of the inner margin. Abdominal sterna (male and female) without any fovea on each side. Aedeagus (Figs. 17C and D) with median lobe slightly sickleshaped, basal lamina markedly arcuate; internal sac without sclerotized sclerites, with one difuse tubelike membrane.

DESCRIPTION: Length of Holotype: $1.2 \mathrm{~mm}$. Length of paratypes: 1.0-1.2 $\mathrm{mm}$ (males and females). Head (Figs. 9-10) slightly longer than wide [length: $0.22-0.26 \mathrm{~mm}$ (males) and 0.27-0.29 $\mathrm{mm}$ (females), width: $0.20-0.26 \mathrm{~mm}$ (males) and $0.26 \mathrm{~mm}$ (females)] with hexagonal microsculp- ture, not depressed in the middle of the frons; vertex without transversal microsculpture, absence of a file (pars stridens) (Fig. 11). Cephalic chaetotaxy (large setae): Labrum with three pairs of setae (those on sides longer), one pair on sides of clypeus and one pair close to frontal sulcus, a pair of supraocular setae present over each eye and one posterior pair of setae between vertex and lateral carinae. Antennae moniliform, mouth-parts (Fig. 10) with no special features, as for other members of the genus. Pronotum quadrangular (Fig. 12), as long as wide [length: $0.26-0.30 \mathrm{~mm}$ (males) and $0.29-0.31 \mathrm{~mm}$ (females), width: $0.24-0.29 \mathrm{~mm}$ (males) and 0.27-0.29 mm (females)], with hexagonal microsculpture, slightly narrowed towards posterior angles which are marked; disk flattened, with one central and two lateral slight sulci on each side; anterior margin slightly arcuate; lateral mar- 
gins slightly rounded, without minor denticles near the posterior angles; disk faintly depressed near the posterior margin, this slightly arcuate. Chaetotaxy: three longitudinal series of minute setae between midline and lateral margins directed anteriad and inward; one anterior seta on each side in anterior quarter, one posterior seta on hind angle; five-six pairs of setae near the anterior margin. Elytra (Figs. 13-14) twice longer than wide [length: 0.48-0.55 $\mathrm{mm}$ (males) and 0.56-0.59 mm (females), width: $0.25-0.29 \mathrm{~mm}$ (males) and 0.26-0.29 $\mathrm{mm}$ (females)], parallel and oval posteriorly, with hexagonal microsculpture and a slightly longitudinal carinae at the beginning of seventh stria; depressed on the disk; transverse scutellar organ present near the beginning of suture (Fig. 13); scutellar region not punctured; humeral angles rounded, with a minor tooth at the beginning of carinae; lateral margins slightly serrate, teeth decreasing in size posteriorly; apical margin (Fig. 14) with one tooth coinciding with end of seventh stria, presence of a parasutural tooth. Chaetotaxy: Part of the pubescence of the disk arranged in three lines, these short setae are erect and slightly directed anteriad; umbilicate series with 4 setae in the front group and 2 in the hind group (4+2) (Fig. 13). Legs with robust femora, mace shaped, tibiae dilated distally in both sexes; trochanters of third pair round-shaped, similar in both sexes (Figs. 15-16), protarsus with segments not dilated. Abdominal sterna II and III (males and females) without fovea on each side (Figs. 15-16). Male genitalia (Figs. $17 \mathrm{C}$ and D) in lateral aspect (Fig. 17C) with median lobe almost right, basal lamina markedly arcuate; median lobe in dorsal aspect (Fig. 17D) with apex more or less large; internal sac in central area without sclerites, presence of a tubiforme membrane (Fig. 17C); parameres bisetulose apically. Female genitalia (Fig. 18B) with ovipositor gonocoxites weakly sclerotized, each one in ventral aspect with 1 apical seta and 1 medium seta; internal genital tract with spermathecal duct short and spermatheca barrel shaped.

Etymology: This new species is dedicated to Professor Eduardo Frias Crespo, who has greatly contributed to the taxonomic, phylogenetic and ecologic knowledge of the Portuguese amphibian and reptilian faunas, and become a remarkable academic reference to the senior author.

Affinities (see also Table 2): The new species belongs to the outereloi group based on umbilicate series of elytron with four setae in the anterior group and two setae in the posterior group
$(4+2)$ and the apical edge of elytron with two teeth. Within the outereloi species group, the new species as well as T. intermedia Zaballos, 1986 do not exhibit denticles in lateral margins of pronotun near the hind angles. The new species is akin to T. quadridentata Coiffait, 1968, T. navarica Zaballos \& Wrase, 1998, T. atienzai Zaballos \& Ruiz-Tapiador, 1997, T. estrellae Zaballos \& Ruiz-Tapiador, 1997, T. bullaquensis Zaballos \& Ruiz-Tapiador, 1997 and T. singularis Serrano \& Aguiar, 2000 because of the presence of two lateral sulci on each side of pronotum, to T. quadridentata, T. belenae Zaballos, 1983, T. intermedia, T. jeannei Zaballos, 1989, T. bullaquensis and T. elenae Serrano \& Aguiar, 2002 because of the presence of two teeth in the apical margin of elytron, to T. outereloi Novoa, 1979, T. quadridentata, $T$. belenae, $T$. intermedia, $T$. navarica, $T$. singularis, T. gomesalvesi Serrano \& Aguiar, 2002, T. laurentii Magrini, 2000 and T. bazi Ortuño, 2000 because of the absence of thorn shaped hind trochanters in males, to T. outereloi, $T$. quadridentata, $T$. belenae, T. intermedia, $T$. toriboi Ortuño, 1988, T. jeannei, T. singularis, $T$. gomesalvesi, T. laurentii and T. bazi because of the absence of lateral fovea in abdominal sternum II (one or two) and to T. intermedia, T. jeannei, $T$. atienzai, T. estrellae, T. bullaquensis, T. singularis, $T$. elenae and $T$. gomesalvesi because of the pattern of apical and medium gonocoxite setae (1+1). Typhlocharis crespoi n. sp., T. outereloi, $T$. singularis, and $T$. laurentii exhibit a similar pattern of form (slightly arcuate and pointed apex) of the median lobe of the aedeagus in lateral view. However, differences in the shape of the apex of the median lobe (dorsal view), left paramere and internal sac separate the new species from all the other species belonging to this group. The new species together with T. quadridentata and T. singularis, by the known data (Magrini, 2000; Serrano \& Aguiar, 2002), are the smallest ones of the outereloi group.

Taking into account the analysed characters, the new species seems to have a closer relationship with $T$. intermedia, $T$. quadridentata and $T$. singularis. The first species was found near Ciudad Real (Spain) and the latter two in several localities of Portugal (Coiffait, 1968; Serrano \& Aguiar, 2002).

Note that in the locality of Pincho, where T. crespoi n. sp. was discovered, lives also Geocharis femoralis Coiffait, 1969 another endogean carabid. Both species are partially syntopic (see also Serrano \& Aguiar, 2006c). 


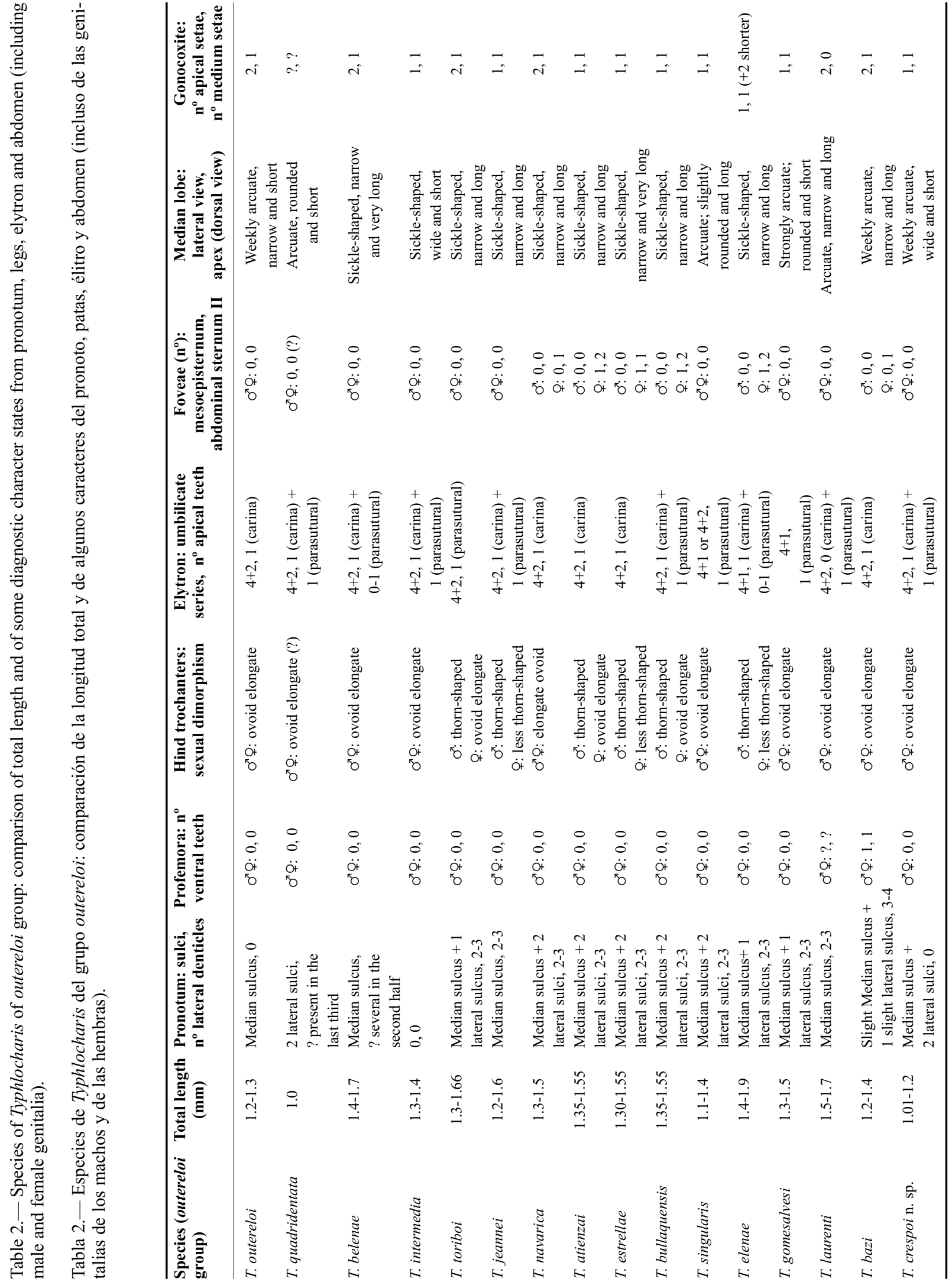


Keys to all species of Typhlocharis diecki Group and to species of Typhlocharis outereloi Group from Portugal

The diecki species group includes the following known nine species: T. diecki, T. santschii, T. besucheti, T. carmenae, T. farinosae, T. gonzaloi (male unknown), T. lunai, $T$. martini and $T$. rochapitei $\mathrm{n}$. $\mathrm{sp}$. On the other hand, the outereloi species group includes the following five species from Portugal: T. quadridentata (female unknown), T. singularis, T. elenae, T. gomesalvesi and T. crespoi $\mathrm{n}$. sp.

\section{T. diecki Group}

Taking into account the identification key given by Andújar et al. (2008) for the diecki group species, the new species can enter in this key, with some modifications, as follows:

5. Sutural angle of elytron rounded. Abdominal sternum II of female with or without lateral fovea. Length $1.2 \mathrm{~mm}$ or less ... 6

- Sutural angle of elytron dentate. Abdominal sternum II of female with lateral fovea. Length $1.5 \mathrm{~mm}$ or more

6. Base of elytron perpendicular to lateral margin, shoulder evident, antennomeres 1-3 not moniliform. Abdominal sternum II of female without lateral fovea. Species from Pego (Alicante) .... T. gonzaloi

- Base of elytron extended diagonally to shoulder, latter indistinct, antennomeres 1-3 moniliform. Abdominal sternum II of female with lateral fovea. Species from Navarra and Zaragoza T. diecki

7. Disc of elytron with a clear fovea between suture and the longitudinal carina, at the level of the posterior group of umbilicate setae. Metatrochanter of female unusually long. Species from Montes de Toledo ......

\section{T. carmenae}

- Disc of elytron without fovea .. 8

8. Metatrochanter of male thorn-shaped. Abdominal sternum II of female with a conspicous posteriolateral fovea on each side. Species from Montes de Toledo T. farinosae

- Metatrochanter of male ovoid elongate. Abdominal sternum II of female with slight posteriolateral fovea on each side. Species from Alcabideche

T. rochapitei $\mathrm{n}$. $\mathrm{sp}$.

\section{T. outereloi Group (Portugal)}

1. Lateral margins of pronotum with denticles near the posterior angles. Disk of elytron with four rows of setae. Umbilicate series $4+2$ and/or 4+1. Internal sac of median lobe of aedeagus with sclerites ............ 2

- Lateral margins of pronotum without denticles near the posterior angles. Disk of elytron with three rows of setae. Umbilicate series $4+2$. Internal sac of median lobe of aedeagus diffuse, without sclerites. Spermatheca barrel-shaped. Species from Pincho (Algarve Province) T. crespoi n. sp.

2. Apical edge of elytron with two distinct teeth, one in the end of longitudinal carina, other near the sutural angle (parasutural)

- Apical edge of elytron with only a distinct parasutural tooth

3. Length of body $1.0 \mathrm{~mm}$. Metatrochanter ovoid elongate. Median lobe of aedeagus slightly arcuate, apex largely rounded (lateral view) (Fig. 2D, Coiffait, 1968). Species from Silves, Loulé, Sta Bárbara de Nexe, São Brás de Alportel and Boliqueime (Algarve Province) T. quadridentata

- Length of body 1.4-1.9 mm. Metatrochanter strongly thorn-shaped (male) or slightly thorn-shaped (female). Abdominal sternum II with one deep posteriolateral fovea on each side. Median lobe of aedeagus strongly sickle-shaped, apex acute (lateral view) (Fig. 2a, Serrano \& Aguiar, 2002). Spermatheca barrel-shaped. Species from Estremoz - Vimieiro, RedondoBencatel, Granja and Mértola (Alto and Baixo Alentejo Provinces)

T. elenae

4. Pronotum with two lateral sulci. Apical edge of elytron strongly sinuate between the seventh stria and the parasutural tooth. Umbilicate series $4+2$ (very rarely 4+1). Median lobe of aedeagus with ventral side almost straight, apex acute (lateral view) (Fig. 2a, Serrano \& Aguiar, 2000). Species from Montemor-o-Novo, Estremoz - Vimieiro, Redondo-Bencatel, Monte Trigo, Lousal and Mértola (Alto and Baixo Alentejo Provinces) T. singularis

- Pronotum with one lateral sulcus. Apical edge of elytron slightly sinuate between the seventh stria and the parasutural tooth. Umbilicate series $4+1$. Median lobe of aedeagus with ventral side curved, apex slightly rounded (lateral view) (Fig. 2c, Serrano \& Aguiar, 2002). Species from Granja (Baixo Alentejo Province)

T. gomesalvesi

\section{ACKNOWLEDGMENTS}

We are grateful to Telmo Antunes for photographic assistance. We are indebted to José Marino Serrano (Facultad de Veterinaria, Murcia) and to one anonymous reviewer for their helpful comments and suggestions that improved the manuscript. This work was partially financed by Centro de Biologia Ambiental (CBA). 


\section{References}

Andeweg, B., 2002. Cenozoic tectonic evolution of the Iberian Peninsula. Causes and effects of changing stress fields. Vrije Universiteit Netherlands Research School of Sedimentary Geology publ. no 20020101. Amsterdam. 178 pp.

AndúJar, C., Lencina, J. L. \& Serrano, J., 2008. Typhlocharis Dieck, 1869 (Coleoptera, Carabidae, Anillini): a new species from the Iberian Peninsula, with notes about its relationships and the evolution of the diecki species group. Zootaxa, 1842: 35-44.

CoIffait, H., 1968. Nouveaux Anillini du Maroc et du Sud de la Péninsule Ibérique. Bulletin de la Société des Sciences Naturelles et Physiques du Maroc, 48(34): 55-66.

CoIffait, H., 1971. Contribution à la connaissance du genre Typhlocharis (Col. Carabidae). Description d'une espèce nouvelle du Portugal. Annales de Spéléologie, 26(2): 463-467.

JeAnNe, C., 1973. Sur la Classification des Bembidiides endogés de la Région Euro-Méditerranéenne (Col. Carabidae, Bembidiinae, Anillini). Nouvelle Revue d'Entomologie, 3(2): 83-102.

JEANNEL, R., 1963. Monographie des «Anillini», Bembidiides endogés (Coleoptera Trechidae). Mémoires $d u$ Muséum National d'Histoire Naturelle, (N.S.) Série A Zoologie, 28(2): 33-204.

Magrini, P., 2000. Due nuovi Typhlocharis Dieck, 1869 di Spagna (Insecta Coleoptera Carabidae). Quaderno di Studi e Notizie di Storia Naturale della Romagna, 13, supplemento: 1-10.

OrtuÑo, V. M., 2005. A new endogaeic ground beetle from easter Spain: Typhlocharis gonzaloi sp. n. (Coleoptera: Carabidae: Anillini). Revue Suisse de Zoologie, 112(3): 639-646.

Oosterbroek, P. \& Arntzen, J. W., 1992. Area-cladograms of Circum-Mediterranean taxa in relation to Mediterranean paleogeography. Journal of Biogeography, 19: 3-20.

Serrano, A. R. M. \& Aguiar, C. A. S., 2000. Description of two new endogean beetle species (Coleoptera, Carabidae) from Portugal. Boletim da Sociedade Portuguesa de Entomologia, 7(13): 149-158.

Serrano, A. R. M. \& Aguiar, C. A. S., 2001. Three new endogean beetles (Coleoptera, Carabidae) from Portugal. The Coleopterists Bulletin, 55(1): 172-180.
Serrano, A. R. M. \& Aguiar, C. A. S., 2002. The genus Typhlocharis Dieck, 1869 (Coleoptera: Carabidae) in Portugal: description of two new species and faunistic notes. Boletim da Sociedade Portuguesa de Entomologia, 7(16): 181-197.

Serrano, A. R. M. \& Aguiar, C. A. S., 2006a. Two new species of Typhlocharis Dieck, 1869 (Coleoptera, Carabidae) from Portugal and notes on the related species. Deutsche entomologische Zeitschrift, 53(2): 223-234.

Serrano, A. R. M. \& Aguiar, C. A. S., 2006b. Two new species of Typhlocharis Dieck, 1869 of the silvanoides group from Portugal (Coleoptera, Carabidae). Animal Biodiversity and Conservation, 29(1): 9-18.

Serrano, A. R. M. \& Aguiar, C. A. S., 2006c. New species and new data on the genus Geocharis Ehlers, 1883 (Coleoptera: Carabidae) from Portugal. Annales de la Société entomologique de France, (n.s.), 42(1): 79-89.

Serrano, A. R. M. \& Aguiar, C. A. S., in press. A new species of the genus Geocharis Ehlers, 1883 and some faunistic data on endogean carabids from Portugal (Coleoptera: Carabidae). Revue Suisse de Zoologie.

Serrano, A. R. M. \& Aguiar, C. A. S. \& Proença, S. J. R., 2005. Two new species of Typhlocharis Dieck of the Group gomezi from Portugal (Coleoptera: Carabidae). The Coleopterists Bulletin, 59(2): 239249.

Serrano, J., 2003. Catálogo de los Carabidae (Coleoptera) de la Península Ibérica. Monografias S.E.A., 9: 1-130.

ZABAllos, J. P. \& RUIZ-TAPIADOR, I., 1997. Nuevos Typhlocharis Dieck (Coleoptera, Caraboidea, Trechidae) de España. Graellsia, 52: 95-106.
Recibido, 18-VII-2008
Aceptado, 5-XI-2008
Publicado, 29-XII-2008 